\title{
Chapter 7 \\ Participatory Research on Heritage- and Culture-Based Development: A Perspective from South-East Europe
}

\author{
Janez Nared and David Bole
}

\begin{abstract}
The objective of the chapter is to highlight the relevance and implementation of culture- and heritage-led regional and local development in South-East Europe. By implementing the participatory research methodology at two major events in Europe, we analysed the practitioners' views on the topics of culture- and heritage-led development. Our results showed that culture and heritage are characteristic and unique and could provide a distinctive added value for regional development as a branding tool, a factor of motivation, community empowerment and a strong element of local identity. Although protection is an important issue in cultural heritage, it should be complemented by education, identification, tourism and development, especially by fostering the economic potentials reflected in increased tourism flows and resulting multiplier effects. Culture and heritage are deeply embedded in a local context, so local communities must be closely involved in the management structures and their views and requirements must be considered. Participatory planning of such sites is welcomed since it includes "negotiating" solutions horizontally and vertically with the main planning goal of making positive changes in local communities and integrating both perspectives (conservation and development) to achieve sustainable futures.
\end{abstract}

Keywords Culture $\cdot$ Heritage $\cdot$ Development $\cdot$ Economic potentials $\cdot$ Participatory research $\cdot$ Sustainable development

\subsection{Introduction}

South-East Europe is rich in cultural heritage, and its varied culture is still struggling with its own development path and transition to a post-socialist and postwar economic era. To tackle this problem, the European Commission launched the

\footnotetext{
J. Nared $(\bowtie) \cdot$ D. Bole

Research Centre of the Slovenian Academy of Sciences and Arts, Anton Melik Geographical Institute, Ljubljana, Slovenia

e-mail: janez.nared@zrc-sazu.si

D. Bole

e-mail: david.bole@zrc-sazu.si 
South-East Europe Transnational Cooperation Programme that addressed culture as an important part of the sustainable development of the entire region (Nared et al. 2014).

Culture and cultural heritage can be seen as a development factor, as they can be used in various ways to contribute to the quality of life in individual communities. Their economic potential is reflected in increased tourism flows and resulting multiplier effects, in regional marketing and branding, as well as having an important role in education, identification and image (Nared et al. 2013). As said by Graham (2001, p. 1006), cultural heritage

... is an economic resource; one exploited everywhere as a primary component of strategies to promote tourism, economic development and rural and urban regeneration. But heritage is also a knowledge, a cultural product and a political resource and thus possesses a crucial socio-political function.

In a wider context, local culture is an important component of regional development, and its protection and development must be closely integrated with planning and developing the entire region. The initial development resource represented by local culture must be evaluated and a great deal of knowledge, creativity and innovation must be invested into it in order to gain the developmental benefits for the community. Culture-based development relies on local actors and their relations and is an intricate combination of a primary source (local culture) together with the human and social capital of the region or the local community (Bole et al. 2013). As other authors have determined (Bigaran et al. 2013; Šmid Hribar and Ledinek Lozej 2013), culture can only be an initial development resource if it is suitably evaluated, negotiated and implemented by a myriad of different stakeholders.

According to the recommendations set out in the Convention (1972), heritage, similarly to culture, should be included in the community life. However, it is important not to exceed the carrying capacities or threaten the authenticity of the area or monument (Ringbeck 2008; Ruoss and Alfarè 2013; Iliopoulou-Georgudaki and Alfarè 2014) and to ensure that the measures do not reduce the exceptional universal values of a specific protected monument. In this way, managing cultural and heritage sites combines both protection and development, each having its own specificities, which calls for integral planning of the cultural heritage sites. This requires constant interactions among the involved stakeholders, which demonstrates that the participation process is of utmost importance (Nared et al. 2013, p. 359). Foremost, the participatory process should be a bottom-up process taking place in real planning areas and solving real issues (e.g. Alfarè and Nared 2014; Nared 2014), whereas it might be supplemented by a participatory research that binds experts and practitioners in searching for more general and strategic solutions.

Our initiatives supported the development process in South-East Europe by tackling both issues mentioned above. We studied the relevance and implementation of culture and cultural heritage in regional and local development, and we were involved in the participatory planning at the broader scale. The latter meant carrying out participatory research for guiding development models, strategies and recommendations in the entire South-East Europe. Since the local cases are often very specific and thus 
difficult to transfer to other areas, participatory research-driven results that involve stakeholders and experts from the entire South-East Europe and beyond could be more useful and internationally relevant. To this end, we present the results achieved within two participatory processes, the first taking place in Cetinje, Montenegro and the other in Heraklion, Greece. Both considered the local culture and cultural heritage as factors of local and regional development. In addition to presenting the outcomes of this research, we wish to reflect on the positive and negative aspects of carrying out participatory research with experts and practitioners. We believe this will be beneficial not only to those interested in culture- and heritage-based development, but also any other researchers who are enquiring into a participatory or any other kind of action research.

There are many studies focusing specifically on the role of cultural heritage in economic development (the latest being Dümcke and Gnedovsky 2013; Tudorache 2016; Kouřilová and Pělucha 2017). The European Commission (2014) followed suit, establishing that cultural heritage and cultural activities are seen as having significant economic and social impacts, not just through cultural tourism, but also through fostering cultural and creative industries. Culture-based development has become a buzzword in many cities, towns and regions where new development strategies and new growth are sought (Tubadji 2012). Large flagship culture and cultural heritage projects are often central to this kind of development with museums, exhibitions, festivals and similar activities, all falling under the scope of cultural tourism. Yet some studies show that large-scale cultural projects do little for new development if they are not positioned into the existing local context and supported by the local practitioners and community (Grodach 2008, 2010). Sacco et al. (2013) provided a critique of culture- and heritage-led development initiatives and of researchers taking an either overly instrumental, over-engineered or parochial attitude towards it. In contrast, they propose that culture-led development should be based on negotiating the economic and social conditions that enable the culture to be performed and executed through the proper strategic coordination with the local economy and community (2013). We consider participatory research to be a way to facilitate this coordination, mainly because the final objective of a participatory research is not only to gain new knowledge but also to facilitate the local communities and practitioners with open debates about developmental, societal and other issues (Bole et al. 2017).

However, up to now, these open debates have been underrepresented and rarely used for policy advice and policy recommendations. The chapter tries to fill this gap and provides the explanation on how a participatory research can lead to coordinated and consented solutions in the field of culture- and cultural heritage-led development.

The aim of this chapter is to analyse the practitioners' views on the topics of culture- and heritage-led development. To this end, we have formed the following research questions tackled by the participatory research:

1. What is the role of culture and cultural heritage in sustainable development?

2. How to reflect the uniqueness and non-renewable character of cultural heritage?

3. Which are the economic potentials of cultural heritage and culture in general? 
4. What is the proper territorial setting for fostering cultural heritage and culture?

5. Which are the lessons learned from the South-East Europe Programme perspective?

\subsection{Method}

The research was conducted in the area covered by the former transnational cooperation programme South-East Europe with two transnational cooperation projects (CHERPLAN and SY_CULTour), which dealt with the planning of cultural heritage sites and the development of cultural tourism in rural areas.

The participatory research took place in the scope of two international conferences, one taking place in Cetinje, Montenegro (Fig. 7.1), attended by 31 experts from nine countries, and the other in Heraklion, Greece, attended by 137 experts from 11 countries. In this type of research, the methodological question arises as to which groups of persons should or must be involved, especially in view of the fact that different groups have developed different knowledge in the area under study (Bergold and Thomas 2012). We identified three types of participants:

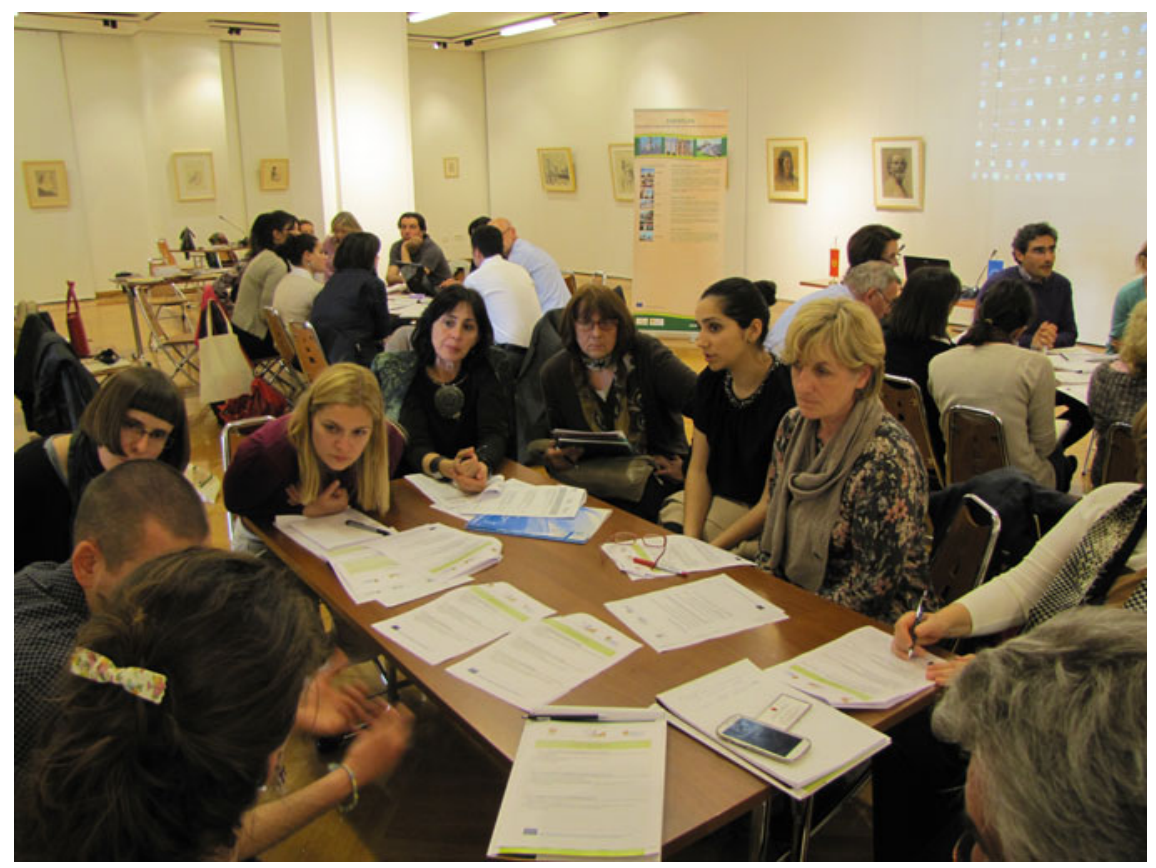

Fig. 7.1 Workshop is Cetinje, Montenegro. Photograph Janez Nared 
- The first type was the participants whose involvement was pivotal and were invited directly because the participatory process would not be sensible without their knowledge. These were mainly professionals and practitioners in culture-led and heritage-led development, its management and planning. They included also policymakers, representatives of responsible agencies and organisations (UNESCO, responsible ministries of national states, planning authorities, etc.).

- The second participant type was those who expressed an interest in cooperating themselves since they have been involved or are interested in this kind of development. The sessions were open to the public and those participants applied to be part of this research. They were mostly members of certain NGOs (culture, heritage, tourism), representatives of territorial authorities (regions, local communities).

- The third type was researchers and academics. They were either steering the process as facilitators and were involved from the beginning or were invited to the interactive sessions because they were experts in certain fields.

Overall, we believe that the participant selection adhered to the fundamental principles of conducting this kind of research (Bergold and Thomas 2012): we achieved a balanced mix of researchers and practitioners (co-researchers); and second, by having an open-door policy and enabling participants to "register" to the events, we did not exclude anyone or any kind of knowledge (in the case of the Cetinje conference, a number of external was rather limited).

From the methodological side, we decided to carry out the research with a smaller interactive session with all the participants (workshop). In both cases, the participants participated in the interactive sessions led by the preselected facilitators. The participants at each conference were divided into groups and each designated facilitator spent half an hour with each group covering a specific topic. After half an hour, the facilitators switched, so that each group had a chance to provide their opinions and policy recommendations for each of the topics. In this way, we ensured that each individual or group had a voice and a chance to express their knowledge in a comfortable setting. In the end, the facilitators consolidated the answers and presented them in the plenary session, which also provided room for corrections if anyone felt they had been misunderstood. In addition, presenting the results of all the groups enabled us to draw some conclusions and identify how the discussed fields interlinked together. This is very important because the research process has to be self-reflective and different perceptions of the new knowledge should be negotiated among the participants (Bergold and Thomas 2012).

The research design proved useful, as it enables everyone to have a voice on the issue; furthermore, as the same questions were repeated from group to group, the facilitator is able to augment the questions according to how the discussion develops and to verify the gained results in the following group. The main prerequisites for this kind of research are suitable spaces for the group discussion and that facilitators understand the aim of the research and raise the right questions. It is also desirable that they have sufficient expertise in the field they are discussing. As shown by the results, some facilitators reoriented the questions in a way that suited their mindset 
or past research experience, which did not always contribute to the coherence of the process.

Despite these limitations, the performed research provided well-calibrated results that support the analytical part of the research, as well as provide important inputs into policy-oriented recommendations.

\subsection{Results and Discussion}

The following section presents the final results as discovered and "negotiated" by the participants at the two conferences. First, we present their answers to the five research questions; second, we discuss the wider implications of the participatory research and policy approaches in culture- and heritage-led development.

\subsubsection{The Role of Cultural Heritage in Sustainable Development}

When dealing with cultural heritage and sustainability, several issues arise, like defining a development path and related problems, as well as defining the objectives, the drivers of development and the specific territorial level at which the problem should be addressed. As confirmed by the participants, a partnership among all the relevant actors is of crucial importance and must be understood as an approach or methodology and not as a solution. It can be designed in an objective way and measured by indicators. Furthermore, an important factor in providing sustainable development using cultural heritage is the definition of the problem and the objectives. The various actors that make up the partnership namely have different expectations, knowledge, interests and capacities, which might result in completely different goals and definitions of the problem.

Although they may have all the competencies to steer the development, various territorial levels differ in jurisdiction over the related matter and there may also be discrepancies between their development visions and the visions of the inhabitants and the private sector. It is also necessary to make a decision regarding the concreteness of the strategies and plans as well as their time span. In general, national and regional authorities should take responsibility for the long-term strategic planning, and however, this should be closely coordinated with the aspirations of the local communities that strive for short-term results and solutions that lead to a higher quality of life for the inhabitants. This should help define a long-term path that can be applied in small and short-term steps, guaranteeing constant and visible progress. This finding can be correlated to Kotter's eight steps for institutional change that among others clearly underline the short- and long-term wins that each activity/process should try to achieve (Kotter 1996). The planning should be integrative, so as not to raise con- 
flicts and to respect the needs of all the sectors and all the social groups. Networking and the participative process are of crucial importance here to focus the views and to define an acceptable and adequate development vision; they also enable overcoming the deficiencies of each individual group (for more detailed positive effects of the participatory process, see Nared et al. 2015).

\subsubsection{The Uniqueness and Non-renewable Character of Cultural Heritage}

The main characteristics of cultural heritage are integrity and authenticity, both indicating the unique character of cultural heritage sites as well as other intangible forms of culture. Therefore, when applying development measures, one of the first steps is determining what we would like to protect and how flexible we are at taking these measures. As explained by the participating experts, there are numerous classifications of cultural heritage, but are often incomplete, and there is a constant fear of losing important heritage with its increasing commercialisation and commodification (Bunten 2008). Another threat to cultural heritage is a lack of the financial assets needed to preserve it and the interest of the owners to use their properties according to their aspirations. To enable both protection and development, context-dependent solutions must be developed that reflect the characteristics of each specific area, its heritage and possible development paths. Limits have to be found that ensure the proper maintenance of cultural heritage and that are also flexible enough to enable development where it does not contradict the most unique elements of the heritage.

\subsubsection{The Economic Potentials of Cultural Heritage}

Even though the aim was to explore the economic potentials of cultural heritage beyond tourism, the experts were continuously eliciting tourism as the most obvious and most effective economic use of cultural heritage. The central focus is on the cultural heritage's embeddedness in a specific territory that cannot be reproduced. It is not transferable elsewhere and it thus guarantees a rare economic asset. On the other side, the demand is almost unlimited, as the tourism sector and the number of tourists constantly grow.

The wider benefit of tourism is also the multiplier it creates for a local economy by boosting production and new jobs in the local food and handicraft sectors, the revitalisation of areas and other connected activities. It also broadens the group of people benefiting from the visitors, which is especially important for people who had not been involved before. At the same time, the efficient management of cultural heritage sites must be ensured so as not to exceed the carrying capacity of an area or a monument and particularly not to stimulate hit-and-run tourism that might have 
negative consequences in the longer term. To prevent hit-and-run tourism, cultural heritage sites should strive to balance tourism and heritage conservation, clearly defining the limits and possible solutions and thus avoiding unfavourable impacts on cultural heritage (Ruoss and Alfarè 2013).

However, as observed in Idrija (Slovenia), cultural heritage does not only influence tourism, but can stimulate economic relations through the values and intrinsic culture not only for the cultural sector, but well beyond through openness, creativity, exportorientedness, etc. (Urbanc et al. 2012; Nared et al. 2013; Nared et al. 2014; Zorn et al. 2015).

An additional asset that cultural heritage and culture offer is that the recognition of an area or a specific cultural heritage object enables branding. Uniqueness is economically attractive, meaning private investors can use cultural heritage for branding, and however, the community must control the use of the brand to prevent its inappropriate use. Not only brands for marketable products are based on cultural heritage, but also those for regions, cities and other locations (Nypan 2008). The local economy can also be boosted through a reinforced connection of the products to places, which fosters identification with the product. A particular label can be used to ensure quality control and the origin. Some revenue might also return to a community to be invested into protection and conservation, e.g. the case of Saaremaa vodka using typical windmills from Saaremaa Island (Estonia) as the company's brand and investing some of the revenue into the renovation of the windmills (Eppich et al. 2013).

\subsubsection{The Territorial Setting for Fostering Cultural Heritage and Cultural Values}

Despite the fact that the importance of individual territorial levels differs from country to country, the participants agreed that there is a huge divide among the needs at the local level and the regulation and funding mechanisms at the level of the European Union.

The local level is the one that could ensure bottom-up processes, and the local leaders could make a difference if they were able to acquire sufficient legal and financial power. The voluntary sector and local activists can also be an important driver of development at the local level, often successful without the need to raise funds. Compared to other territorial levels, the local level can be effective in networking, creating local partnerships and engaging the volunteers. Local initiatives include local knowledge and human potential. This result is in accordance with similar research, where it was found that certain social groups, such as the elderly, see small-scale heritage-led tourism as a tool for the community building and strengthening social ties within the area (Bole et al. 2017). Similarly, Scheyvens (1999) observed positive impacts on the social and personal empowerment of tourism in local communities, which reaffirms the need to involve the voluntary sector and local initiatives in heritageand culture-based development. 
Higher territorial levels frequently hold a decisive power in both legal and financial terms, but are often detached from the local needs. Bureaucracy and abstractedness at the European and also national level often hinder local projects. Thus, some more power should be devolved to local levels; the national and regional strategies must fully support the local level as well.

The mismatch between the functional and administrative region can also be an additional hindrance to the effective implementation of projects and would require effective territorial governance by interlinking various territorial levels and a greater flexibility in the decisions.

\subsubsection{Lessons Learned: A Perspective from South-East Europe}

Culture and cultural heritage are important assets that provide income and jobs by fostering tourism and related activities, although they are often neglected by the central governments. This result is also in accordance with other research, where culture was found to improve social cohesion and renew interest in the preservation, interpretation and knowledge of the local culture and cultural heritage (Richards 2007). This calls for an optimisation of the resources and the human and social capital, which can be achieved with a capitalisation and transfer of successfully implemented projects and methodologies, a better communication and presentation of the positive results, as well as with the engagement of volunteers (e.g. elderly, youth), which ensures their social inclusion and at the same time decreases the cost of the projects.

In territorial terms, better cooperation must be ensured among all the territorial levels. It is also crucial to educate the decision-makers about the effects and the role of culture and cultural heritage in the development of an area.

\subsubsection{A Reflection and the Wider Implications of This Research on Future Heritage- and Culture-Based Development}

We believe that this research puts forward at least two major considerations. The first one is connected to the object of the research. The results reiterate the notion that heritage- and culture-led development should be positioned in a local or regional context and encompass a diverse range of stakeholders. These not only include cultural workers, heritage conservation-related experts or development and tourism experts, but also the local community, specific social groups within it and the NGO sector. This diverse set of stakeholders is necessary to create a framework where preservation and development go hand in hand, just as in the case of ecotourism development 
(Scheyvens 1999). This diversity of the involved stakeholders is extremely important to ensure that the "developmental aspect" respects the local culture and preserves the cultural heritage. Vice versa, as shown in some other examples, reviving certain activities for economic gain can also revive certain old knowledge and heritage. There is a good example from Slovenia, where the community of Črni Vrh has revived flax production as a tourist product, sparking renewed interest in the younger population to learn about this almost forgotten and disappearing form of cultural heritage (Bole et al. 2017). Additionally, the results showed that practitioners do not instrumentalise culture and heritage in local development initiatives, which was the criticism of certain initiatives by Sacco et al. (2013). Instrumentalisation, which considers culture and heritage statically as "something out there" to be used to solve a certain problem (Ilmonen 2015) is overly simplistic. It seems that the method used in this research, where the results were negotiated through a series of workshops, enabled the participants to go further and recognise not just the material, but also the nonmaterial developmental capital of culture and heritage (social cohesion, community empowerment, intergenerational dialogue, etc.).

The second reflection concerns the method and its possible use in culture- and heritage-led development. Although the aim of our study was more academic in nature, we believe that participatory methods are very suitable for the future planning of this kind of development. As already explained above, culture- and heritageled development is much too complex and transdisciplinary to be carried out with traditional planning methods. In our case, the participants came from various backgrounds and this participatory method enabled them to discover the broader framework of culture- and heritage-led development. This meant that they were challenged to negotiate rather than "defend" certain notions and thus avoid the traditional conflict between the ideas of conservation on one side and development on the other. Second, participatory planning inherently engages the local community from the very start of the process, meaning that development is more in-tune with its expectations (Mahjabeen et al. 2009). Moreover, it is not possible to plan sustainable development without taking into consideration the cultural processes at the everyday, micro-level (Ilmonen 2015).

Our results partially confirm Nasser's four objectives of the synergy between heritage and development (2003, p. 477):

- The need for long-term planning (the participants in our research corroborated that long-terms goals should be set, but with short-term steps at the local level);

- The need to protect heritage, since it will be degraded if over-exploited (the participants corroborated this statement);

- Change and development are necessary (the participants see culture and heritage as a possible tool for this change);

- Equitable access to heritage and culture resources by the local community and visitors (the participants especially emphasised the role of local communities and vulnerable groups within it).

Our research did have certain limitations, which we have to acknowledge. Our experience was that the process should be moderated in an unbiased manner, or to put 
it simply, the workshop moderators should be listeners and not speakers. This is an unusual position for researchers, because of their traditional role as "wise outsiders". Additionally, this is a long-term process that cannot yield instant results. Getting the right mix of participants is crucial and it can take months to ensure the heterogeneity of the participants. For instance, in Heraklion, we had enough time to invite the interested public and NGOs, while in Cetinje, the selection was more limited. The human input in the organisational matters is also substantial, making this approach quite time-consuming.

\subsection{Conclusion}

The aim of this chapter was to analyse the practitioners' views on the topics of culture- and heritage-led development and to provide an explanation of how a participatory research can lead to coordinated and consented solutions in this field. The participants of this research both in Heraklion and in Cetinje came to similar conclusions that development and heritage can be complementary. The negotiated results from the workshops showed that long-term strategies of culture- and heritageled development at the policy level should be implemented by short-term concrete implementations with participation from the local communities (not forgetting the disadvantaged groups). They also recognised the economic and non-economic benefits of this synergy and the uniqueness of each heritage site and each local culture, rendering uniform and all-embracing plans impossible. They concluded that this kind of development is not possible without respecting the needs and capacities of the local communities and reconfirming that not just economic, but also social and human capital are needed to make and realise the plans of culture- and heritage-based development.

They also pointed out certain shortcomings regarding current heritage- and culture-based development. First is the lack of cooperation between the territorial levels and the national and supra-national levels, which are often detached from the needs of the regional and local levels. Second, if local communities and their cultural specificities are not involved, the threat of commodification and further damage to heritage sites due to a lack of protection or overuse is real.

A participatory planning of such sites is therefore welcomed, since it includes "negotiating" the solutions horizontally (between different participants, those interested in preservation, development or something else) and vertically (between the national, regional or local level of representation). The main planning goal should focus on making positive changes in the local communities by integrating both perspectives (conservation and development) to achieve sustainable futures.

Acknowledgements The authors acknowledge the financial support from the Slovenian Research Agency research core funding Geography of Slovenia (P6-0101). 


\section{References}

Alfarè L, Nared J (2014) Leading a participatory process. In: Nared J, Razpotnik Visković N (eds) Managing cultural heritage sites in southeastern Europe. Založba ZRC, Ljubljana, pp 32-37

Bergold J, Thomas S (2012) Participatory research methods: a methodological approach in motion. Forum: Qualitative Social Research 13(1):1-31. http://dx.doi.org/10.17169/fqs-13.1.1801

Bigaran F, Mazzola A, Stefani A (2013) Enhancing territorial capital for developing mountain areas: the example of Trentino and its use of medicinal and aromatic plants. Acta Geogr Slov 53(2):379-391. https://doi.org/10.3986/AGS53403

Bole D, Pipan P, Komac B (2013) Cultural values and sustainable rural development: a brief introduction. Acta Geogr Slov 53(2):367-370. https://doi.org/10.3986/AGS53401

Bole D, Šmid Hribar M, Pipan P (2017) Participatory research in community development: a case study of creating cultural tourism products. Acta Univ Carol, Geogr 52(2):164-175. https://doi. org/10.14712/23361980.2017.13

Bunten AC (2008) Sharing culture or selling out? Developing the commodified persona in the heritage industry. Am Ethnol 35:380-395. https://doi.org/10.1111/j.1548-1425.2008.00041.x

Convention (1972) Concerning the protection of the world cultural and natural heritage. United Nations educational, Scientific and Cultural Organization, Paris

Dümcke C, Gnedovsky M (2013) The social and economic value of cultural heritage: literature review, EENC Paper. European expert network on culture, Berlin and Moscow

Eppich R, Espada JC, Cruz C, Kulmer A (2013) Good practice for the conservation of urban settlements, vernacular architecture and surrounding landscapes. In: Correia M, Carlos G, Rocha S (eds) Vernacular heritage and earthen architecture. CRC Press, London. https://doi.org/10.1201/ b15685

European Commission (2014) Towards an integrated approach to cultural heritage for Europe. Communication from the Commission to the European Parliament, the Council, the European Economic and Social Committee and the Committee of the Regions. COM (2014) 477

Graham B (2001) Historical geography. In: Smelser NJ, Baltes PB (eds) International encyclopedia of the social \& behavioral sciences. Pergamon. https://doi.org/10.1016/B0-08-043076-7/025766

Grodach C (2008) Looking beyond image and tourism: the role of flagship cultural projects in local arts development. Plan Pract Res 23(4):495-516. https://doi.org/10.1080/02697450802522806

Grodach C (2010) Beyond bilbao: rethinking flagship cultural development and planning in three California cities. J Plan Educ Res 29(3):353-366. https://doi.org/10.1177/0739456X09354452

Ilipoulou-Georgudaki J, Alfarè L (2014) Carrying Capacity. In: Nared J, Razpotnik Visković N (eds) Managing cultural heritage sites in southeastern Europe. Založba ZRC, Ljubljana, pp 97-101

Ilmonen K (2015) The role of culture in regional development work - changes and tensions. In: Go FM, Lemmetyinen A, Hakala U (eds) Harnessing place branding through cultural entrepreneurship. Palgrave Macmillan, London, pp 79-95

Kotter J (1996) Leading change. Harvard Business School Press, Boston

Kouřilová J, Pělucha M (2017) Economic and social impacts of promoting cultural heritage protection by the czech rural development programme 2007-2013. Eur Countryside 9(3):486-503. https://doi.org/10.1515/euco-2017-0029

Mahjabeen Z, Shresha KK, Dee JA (2009) Rethinking community participation in urban planning: the role of disadvantaged groups in Sydney metropolitan strategy. Australas J RegNal Stud 15(1):45-63

Nared J (2014) Participatory Planning. In: Nared J, Razpotnik Visković N (eds) Managing cultural heritage sites in southeastern Europe. Založba ZRC, Ljubljana, pp 28-32

Nared J, Erhartič B, Razpotnik Visković N (2013) Including development topics in a cultural heritage management plan: mercury heritage in Idrija. Acta Geogr Slov 53(2):394-402. https://doi.org/ 10.3986/AGS53404

Nared J, Bole D, Razpotnik Visković N (2014) Tradition and development: the case of Idrija, Slovenia. Regions: quarterly magazine of the Regional Studies Association 293:17-20 
Nared J, Razpotnik Visković N, Cremer-Schulte D, Brozzi R, Cortines Garcia F (2015) Achieving sustainable spatial development in the alps through participatory planning. Acta Geogr Slov 55(2):363-373. https://doi.org/10.3986/AGS.1631

Nasser N (2003) Planning for urban heritage places: reconciling conservation, tourism, and sustainable development. J Plan Lit 17(4):467-479. https://doi.org/10.1177/0885412203017004001

Nypan TM (2008) The economics of built heritage. Cultural heritage and tourism. Department of Cultural Heritage under Ministry of Culture, Vilnius

Richards G (2007) The future of cultural tourism: grounds for pessimism or optimism? In: Richards G (ed) Cultural tourism: global and local perspectives. Haworth Press, New York, pp 329-339

Ringbeck B (2008) Management plans for world heritage sites. A practical guide. German Commission for UNESCO, Bonn

Ruoss E, Alfarè L (2013) Challenging hit and run tourism in cultural heritage sites. In: Marchegiani $\mathrm{L}$ (ed) Proceedings of the international conference on sustainable cultural heritage management: societies, institutions and networks. ARACNE editrice S.r.1, Rome, pp 525-536

Sacco P, Ferilli G, Blessi GT (2013) Understanding culture-led development: a critique of alternative theoretical explanations. Urban Studies 51:2806-2821. https://doi.org/10.1177/ 0042098013512876

Scheyvens R (1999) Ecotourism and the empowerment of local communities. Tour Manag 20(2):245-249. https://doi.org/10.1016/S0261-5177(98)00069-7

Šmid Hribar M, Ledinek Lozej Š (2013) The role of identifying and managing cultural values in rural development. Acta Geogr Slov 53(2):371-378. https://doi.org/10.3986/AGS53402

Tubadji A (2012) Culture-based development: empirical evidence for Germany. Int J Soc Econ 39(9):690-703. https://doi.org/10.1108/03068291211245718

Tudorache P (2016) The importance of the intangible cultural heritage in the economy. Procedia Econ Financ 39:731-736. https://doi.org/10.1016/S2212-5671(16)30271-4

Urbanc M, Nared J, Bole D (2012) Idrija: a local player on the global market. In: Häyrynen S, Turunen R, Nyman J (eds) Locality, memory, reconstruction: the cultural challenges and possibilities of former single-industry communities. Cambridge Scholars Publishing, Newcastle upon Tyne

Zorn M, Nared J, Razpotnik Visković N (2015) Creating new opportunities for an old mining region: the case of Idrija (Slovenia). Ekonomska i ekohistorija: časopis za gospodarsku povijest i povijest okoliša 11(11):123-138

Open Access This chapter is licensed under the terms of the Creative Commons Attribution 4.0 International License (http://creativecommons.org/licenses/by/4.0/), which permits use, sharing, adaptation, distribution and reproduction in any medium or format, as long as you give appropriate credit to the original author(s) and the source, provide a link to the Creative Commons licence and indicate if changes were made.

The images or other third party material in this chapter are included in the chapter's Creative Commons licence, unless indicated otherwise in a credit line to the material. If material is not included in the chapter's Creative Commons licence and your intended use is not permitted by statutory regulation or exceeds the permitted use, you will need to obtain permission directly from the copyright holder.

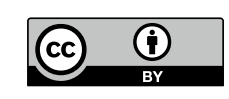

